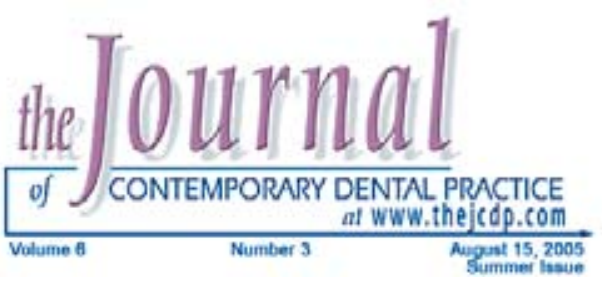

\title{
Prosthetic Rehabilitation of a Child Affected from Anhydrotic Ectodermal Dysplasia: A Case Report
}
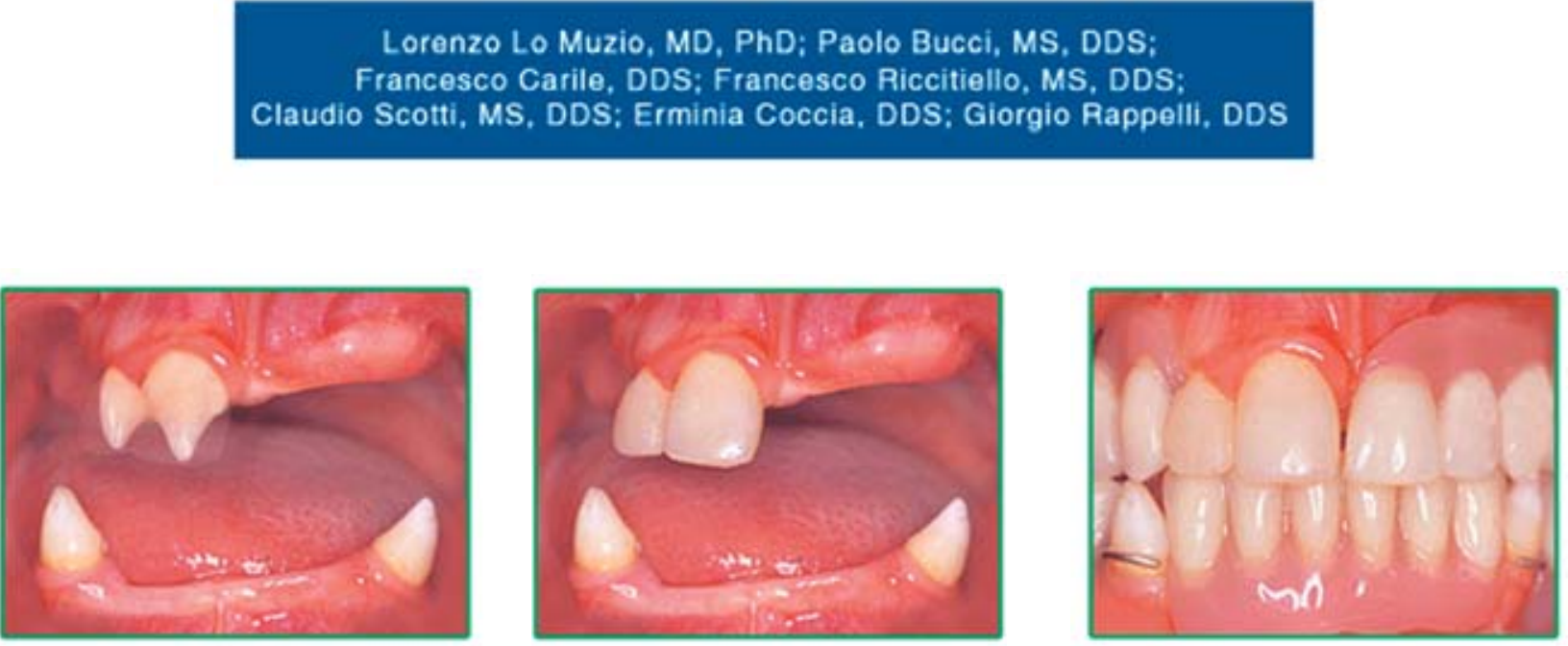

\begin{abstract}
The aim of this clinical report is to describe the management of a young patient, affected by ectodermal dysplasia, during a nine-year period. Dental treatment can vary depending on the severity of the disease (tooth size, morphology, and amount of available alveolar bone). New technologies, such as adhesive dentistry, and new materials, such as composite resin, represent current options in the management of the dental rehabilitation of patients affected by ectodermal dysplasia. Removable partial dentures were used to replace congenitally missing teeth, and composite resin materials were used to restore conical-shaped maxillary teeth to achieve a favorable esthetic result. This option minimized the sacrifice of healthy dental tissue. Prosthodontic and restorative treatment was provided for the psychological and social comfort of the young patient.
\end{abstract}

Keywords: Anhydrotic ectodermal dysplasia, Christ-Siemens-Touraine syndrome, peg-shaped teeth, prosthetic rehabilitation, multidisciplinary management

Citation: Lo Muzio L, Bucci P, Carile F, Riccitiello F, Scotti C, Coccia E, Rappelli G. Prosthetic Rehabilitation of a Child Affected from Anhydrotic Ectodermal Dysplasia: A Case Report. J Contemp Dent Pract 2005 August;(6)3:120-126.

(C) Seer Publishing 


\section{Introduction}

The term "ectodermal dysplasias" indicates a heterogeneous group of hereditary diseases involving the epidermis and its appendages. Freire-Maia-Pinheiro have described 154 patterns of ectodermal dysplasias, divided them into 11 subgroups, and then classified them according to the involved structures (the hair, the teeth, some or all of the sweat glands). ${ }^{1}$

The most frequent form is the ChristSiemens-Touraine syndrome, a recessive autosomal disorder characterized by an anomalous development of the ectodermal structures. Depending on the severity of clinical manifestations, Christ-Siemens-Touraine syndrome can be classified as hypohydrotic ectodermal dysplasia, or as anhydrotic ectodermal dysplasia.

Three clinical signs ${ }^{2}$ are necessary to establish a diagnosis of Christ-Siemens syndrome, and they are as follows:

1. Hypotrichosis (lack of hair)

2. Absence or reduction in number of teeth

3. Absence or diminution of sweat glands

Other manifestations associated with this disease include: skin changes, recurrent ocular infections, chronic rhinitis, dystrophic nails, epistaxis, dysphagia, dysphonia, alopecia, and atypical facies. ${ }^{3}$ Extramedullary haematopoiesis of cranial dura ${ }^{4}$, diminished resistance to respiratory infections ${ }^{5}$, and nasopharyngeal rhabdomyosarcoma ${ }^{6}$ are some of the other disorders that can be present in patients with hypohydrotic or anhydrotic ectodermal dysplasia.

The etiology of this disease is unknown; nevertheless genetic studies showed ectodermal dysplasia is due to a mutation of the gene "EDA" (Ectodermal Dysplasias Anhydrotic). This gene is located in position q12-q13 of the chromosome $X$. The EDA gene encodes a predicted transmembrane protein of 135 amino acids found to be expressed in keratinocytes, hair follicles, and sweat glands. ${ }^{7}$
The mutation responsible for ectodermal dysplasia has been thought to be attributed to a change in the histidine/tyrosine in position 54 of the protein. Another mutation (A1270G) has also been revealed to be responsible for Tyr343Cys substitution in a patient with anhydrotic ectodermal dysplasia. $^{8}$

Due to the presence of only chromosome $\mathrm{X}$, males have Christ-Siemens-Touraine syndrome rather than females. Females are generally healthy bearers. In the rare cases where females are forced bearers, the clinical features of dysplasia are less severe. ${ }^{9}$

Complete or partial anodontia of the primary and permanent dentition and malformation of teeth are the most frequent dental findings. ${ }^{10}$ Peg-shaped incisors and canines are the most frequent dental anomalies. The primary second molar tooth, if present, is mostly affected by taurodontism. ${ }^{11}$ The permanent teeth are small, conical, and tapered toward the coronal surface. ${ }^{12}$ Oligodontia or anodontia may cause the absence or deficiency of alveolar ridges. One typical aspect of ChristSiemens-Touraine syndrome is a patient with a reduced vertical dimension. The vermilion border disappears, the oral mucosa is dry, and the lips become prominent. When these features appear collectively in a child affected by ectodermal dysplasia it results in the characteristic appearance of old age. ${ }^{13}$

The oral rehabilitation of these cases is often difficult, and patients must be attentively followed by a multidisciplinary team involving pediatric dentistry, orthodontics, prosthodontics, and oralmaxillofacial surgery. ${ }^{14}$

The patient's age, the pattern of dysplasia, and the morphology of the alveolar ridges influence dental treatment. ${ }^{15}$ The aim of this clinical report is to present the prosthetic rehabilitation of a patient with anhydrotic ectodermal dysplasia. 


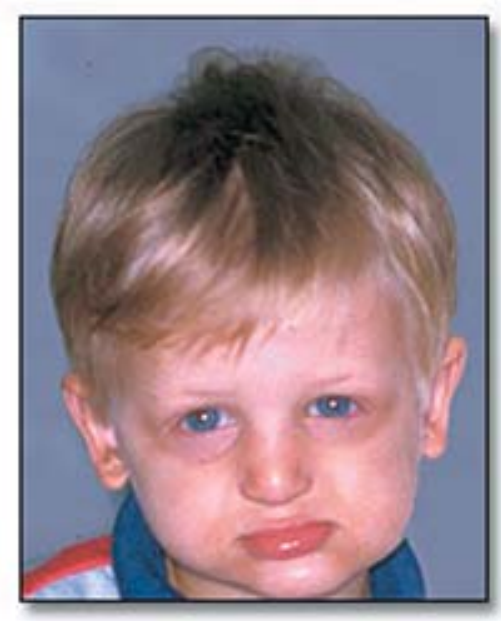

Figure 1. A 5-year old child affected by anhydrotic ectodermal dysplasia.

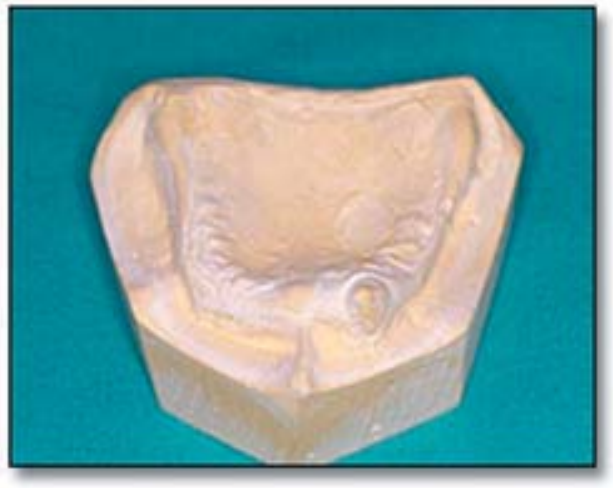

Figure 2. Maxillary diagnostic cast showing the presence and location of one deciduous tooth.

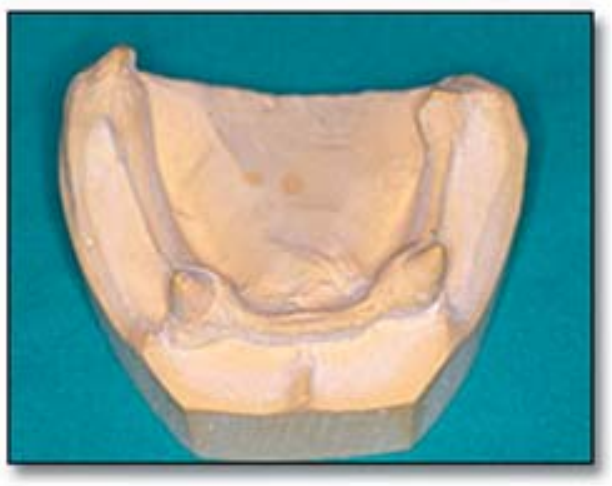

Figure 3. Mandibular diagnostic cast showing an anomalous development of deciduous teeth and alveolar ridges.

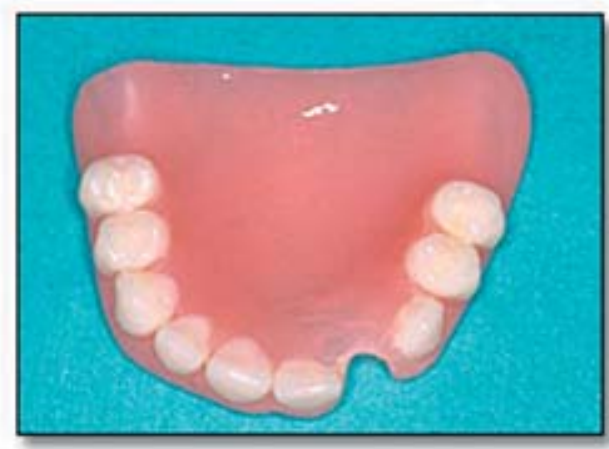

Figure 4. Maxillary partial removable prosthesis is realized in order to ensure a corrected masticatory function.

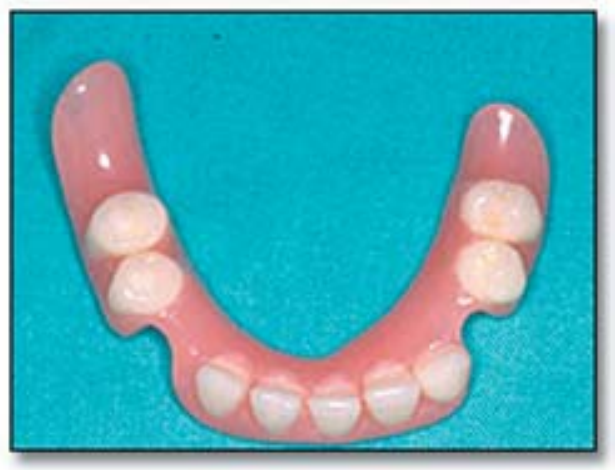

Figure 5. Mandibular partial removable prosthesis.

\section{Case Report}

A 5-year old child with anhydrotic ectodermal dysplasia presented with the peculiar facial anomalies of this disease16 that included: (Figure 1).

- Prominent frontal ridges and chin

- Brittle and fine blonde hair

- A saddle or bulbous pear-shaped nose

- An extended philtrum

- A thin upper lip

- An everted lower lip

- A horizontal groove on the chin

- Thick cheeks and large ears

The oral examination showed the presence of three cone-shaped teeth: two mandibular and one maxillary (Figures 2 and 3). The patient exhibited the loss of vertical dimension, the absence of alveolar processes, and an anomalous development of alveolar ridges. 


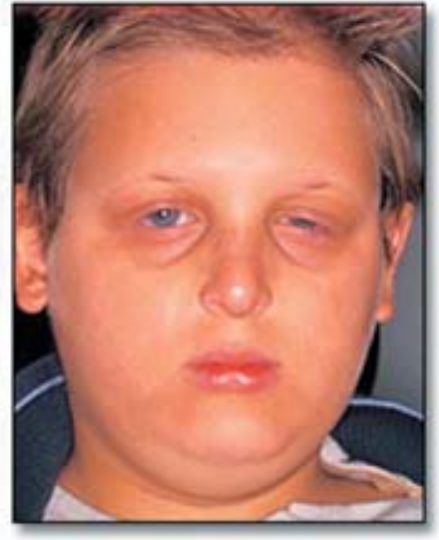

Figure 6. After 7 years,

patient still presents the facial signs of ectodermal dysplasia.

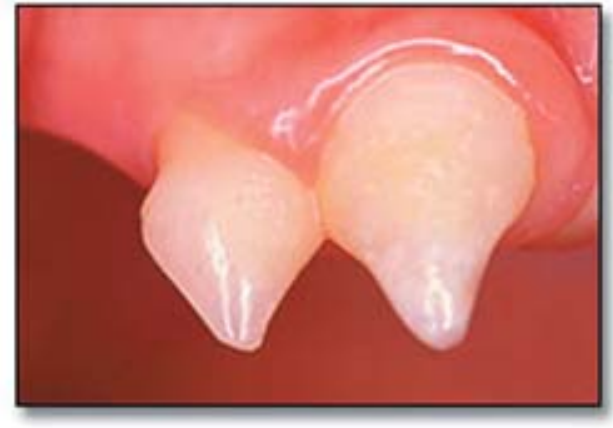

Figure 7. After 7 years, intra-oral examination shows the eruption of another anterior peg-shaped tooth.

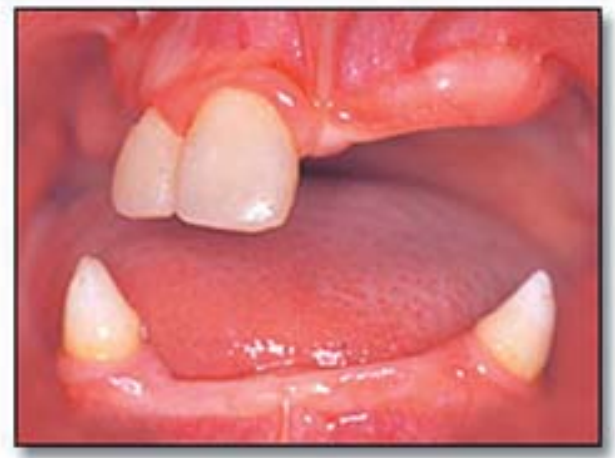

Figure 8. Oral presentation of patient after maxillary teeth were restored with adhesive composite resin.

Due to the age of the patient and the poor amount of alveolar bone, a prosthetic strategy was used. Partial removable prostheses were provided to allow for normal psychological development and a corrected masticatory function (Figures 4 and 5). It is essential to provide continuous evaluation of such patients in order to monitor the status of the dentures and eruption of other permanent teeth.

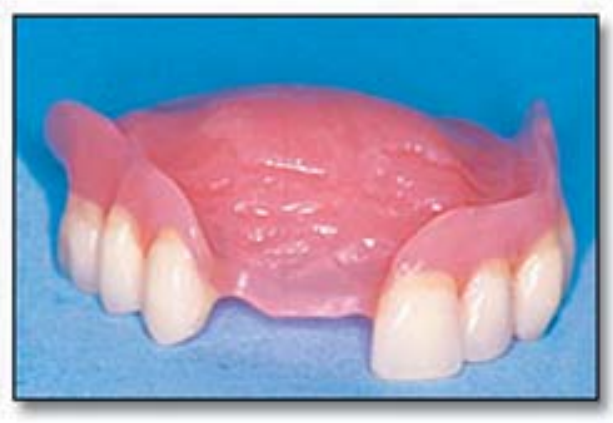

Figure 9. Maxillary partial removable prosthesis.

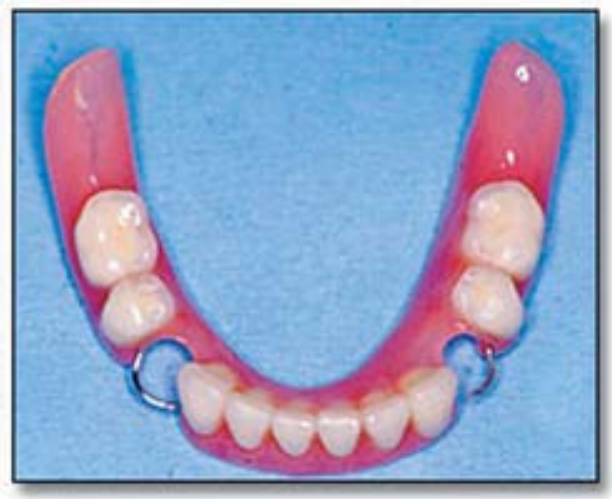

Figure 10. Mandibular partial removable prosthesis.

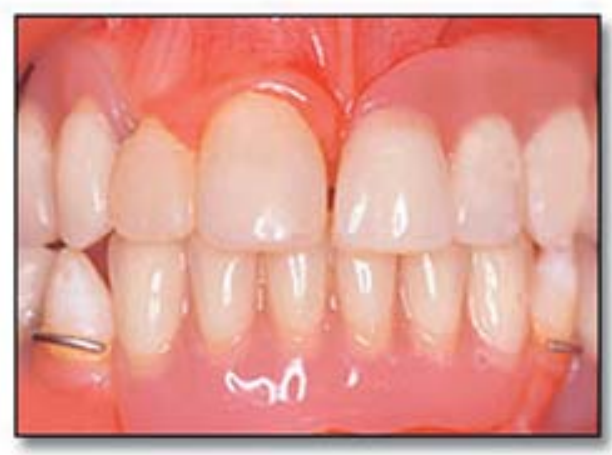

Figure 11. Anterior view of removable dentures in mouth.

After 7 years this patient still presents the same dysplastic aspect (Figure 6), but the intra-oral examination revealed the eruption of another anterior peg-shaped tooth (Figure 7).

In order to restore aesthetic and function again the conical maxillary teeth are reconstructed with composite resin (Figure 8) and partial dentures are remade to accommodate changes in the oral cavity (Figures 9 and 10). This therapeutic choice provided for the psychological and social comfort of our young patient (Figure 11). 


\section{Conclusion}

Development of new techniques and the availabiltiy of innovative materials facilitates the oral rehabilitation of a patient with ectodermal dysplasia. Adhesive resin materials can be used for the conservative and esthetic restoration of peg-shaped teeth. Because anodontic children present with an insufficient amount of alveolar bone, implantation reconstruction surgery is subjected to a greater risk of failure in comparison to more conservative prosthetic treatment. Therefore, in order to improve the function of stomatognathic system, partial dentures were fabricated in conjunction with composite resin restorations.

When it is not possible to utilize implant surgery for patients with Christ-Siemens-Touraine syndrome, prosthodontic rehabilitation is a reasonable choice to facilitate mastication of food as well as for psychological and cosmetic reasons. ${ }^{17}$ It is also important in the management of ectodermal dysplasia to include oral hygiene instruction, fluoride treatments, and periodic recall visits. $^{18}$

\section{References}

1. Pinheiro M, Freire-Maia N. Ectodermal dysplasias: A clinical classification and casual review. Am J Med Genet 1994;53: 153-162.

2. Gardel P, Mercier C, Molhant G. Christ-Siemens-Touraine syndrome. A new case. Rev Stomatol Chir Maxillofac 1984;85: 115-8.

3. Daniel E, McCurdy EA, Shashi V, et al. Ectodermal dysplasia: otolaryngologic manifestations and management. Laryngoscope 2002;112: 962-7.

4. Sitton JE, Reimund EL. Extramedullary hematopoiesis of the cranial dura and anhydrotic ectodermal dysplasia. Neuropediatrics 1992;23: 108-10.

5. Loth M, Waibel M, Albrecht G. Christ-Siemens-Touraine syndrome. Hautarzt 1998;49: 505-8.

6. Cankaya H, Kosem M, Kiris M, et al. Nasopharyngeal rhabdomyosarcoma in a patient with hypohydrotic ectodermal dysplasia syndrome. Auris Nasus Larynx 2002;29: 313-6.

7. Hertz JM, Norgaard Hansen K, Juncker I, et al. A novel missense mutation (402C-->T) in exon 1 in the EDA gene in a family with X-linked hypohydrotic ectodermal dysplasia. Clin Gent 1998;53: 205-9

8. Kobielak A, KobielaK K, Biedziak B, et al. A novel mutation A1270G of the EDA1 gene causing Tyr343Cys substitution in ectodysplasin-A in a family with anhydrotic ectodermal dysplasia. Acta Biochimica Polonica 2003;50: 255-258.

9. Bartstra HL, Hulsmans RF, Steijlen PM, et al. Mosaic expression of hypohydrotic ectodermal dysplasia in an isolated affected female child. Arch Dermatol 1994;130: 1421-4.

10. Merkx MA, Arnold WP. Ectodermal dysplasia: a heterogenic deviation. Ned Tijdschr Tandheelkd. 1995;102: 334-6.

11. Glavina D, Majstorovic M, Lulic-Dukic O, et al. Hipohidrotic ectodermal dysplasia: dental features and carriers detection. Coll Antropol. 2001;25: 303-310.

12. Patel MI. Prosthodontic rehabilitation of a patient with partial anodontia: a clinical report. J Prosthet Dent 2002;88: 132-4.

13. Imirzalioglu $P$, Uckan S, Haydar SG. Surgical and prosthodontic treatment alternatives for children and adolescents with ectodermal dysplasia: a clinical report. J Prosthet Dent 2002;88: 569-572.

14. Bergendal B. Prosthetic habilitation of a young patient with hypohydrotic ectodermal dysplasia and oligodontia: a case report of 20 years treatment. Int J Prosthodont 2001;14: 471-9.

15. Cetiner D, Engel U, Tuter G, et al. Clinical management of ectodermal dysplasia with long term follow up: two case reports. J Clin Pediatric Dent 2001;25: 187-90.

16. Carrington PR, Chen H, Altick JA. Trichorhinophalangeal syndrome, type I. J Am Acad Dermatol 1994;31: 331-6.

17. Gardel P, Leyder P, Molhant G. Christ-Siemens-Touraine syndrome. Completed management is unrelated to the number of years. Rev Stomatol Chir Maxillofac 1985;86: 114-6.

18. Sarvan I, Naidoo S, Norval EJ. Hypohydrotic ectodermal dysplasia: an unusual presentation and management in an 11-year-old Xhosa boy. SADJ 2000;55: 34-7. 
About the Authors

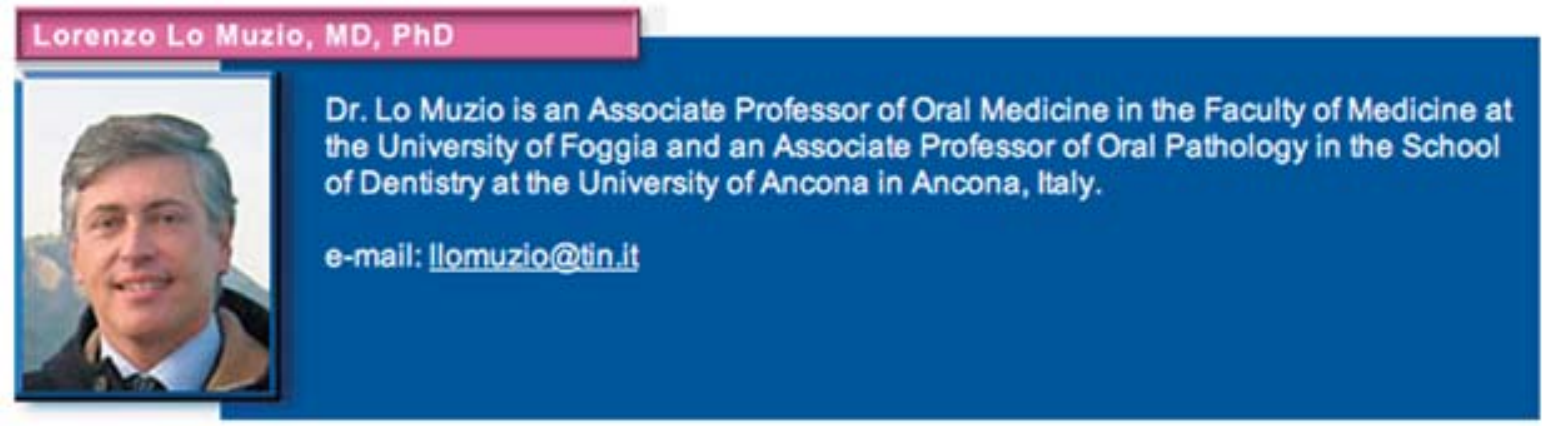

\section{Paolo Buccl, MS, DDS}
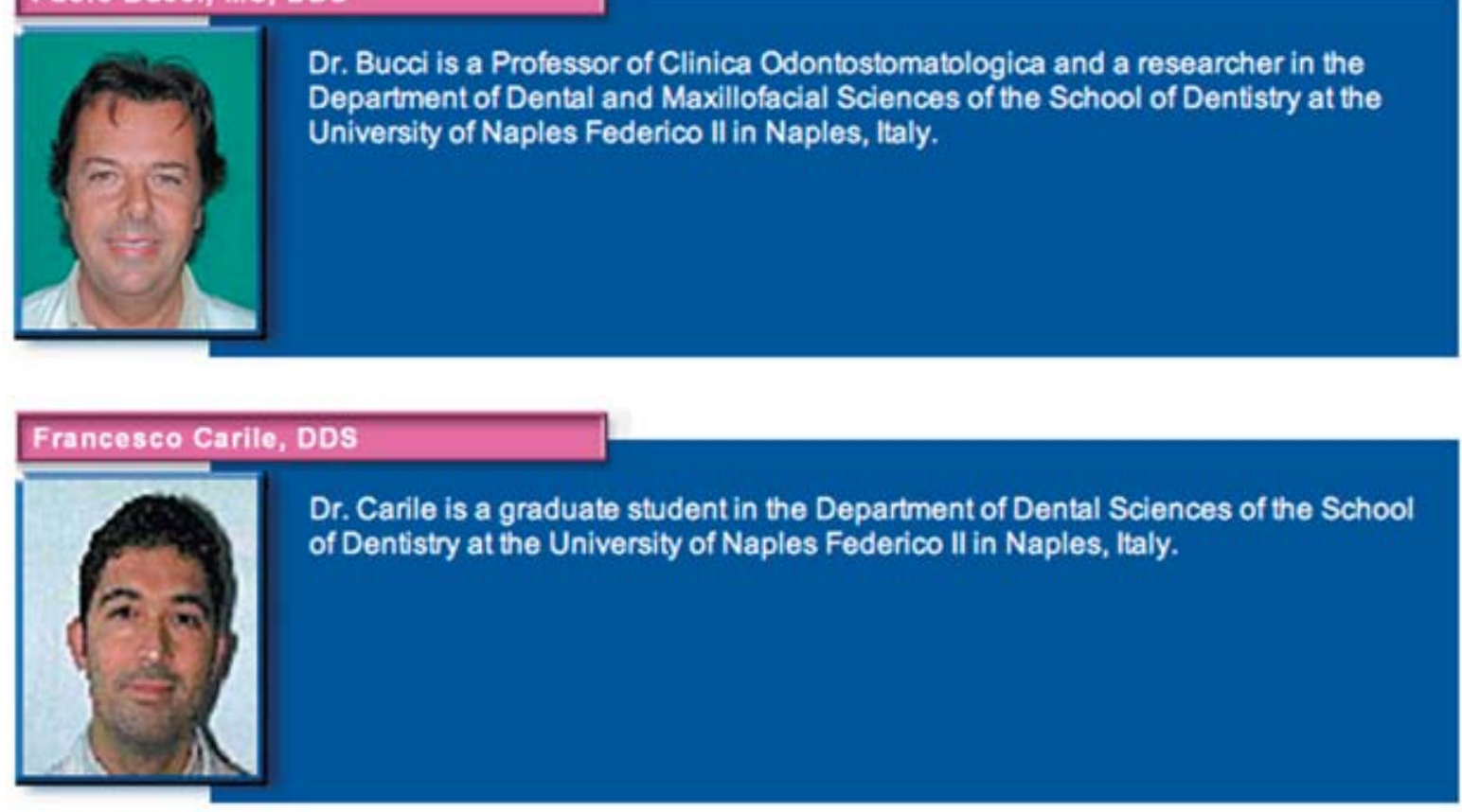

Francesco Riccitiollo, MS, DDS

Dr. Riccitiello is a Researcher in the Department of Operative Dentistry of the School of Dentistry at the University of Naples Federico II in Naples, Italy.

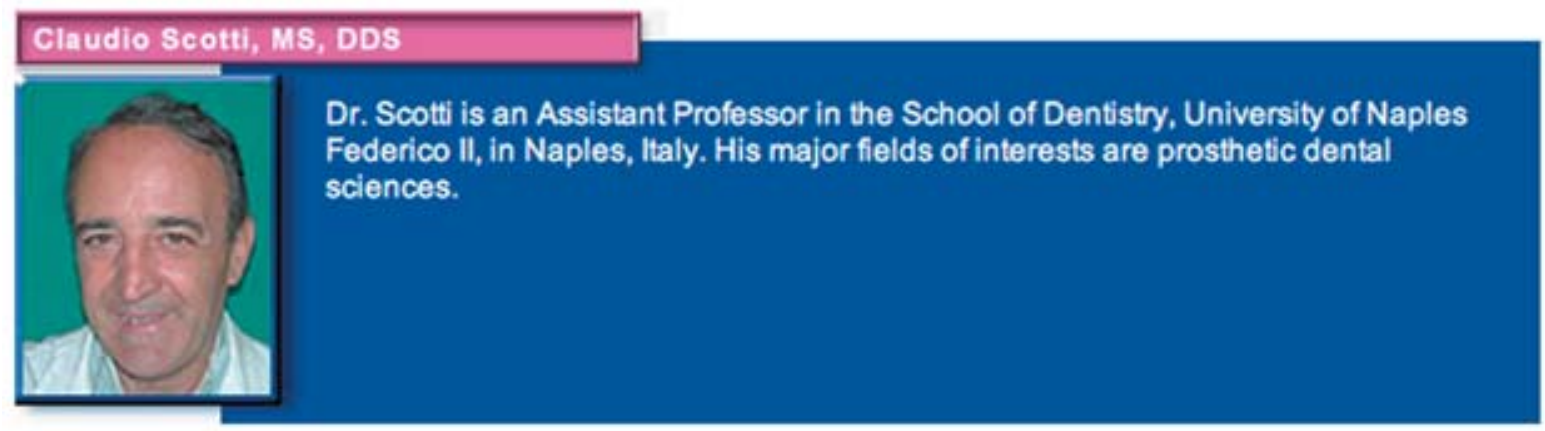



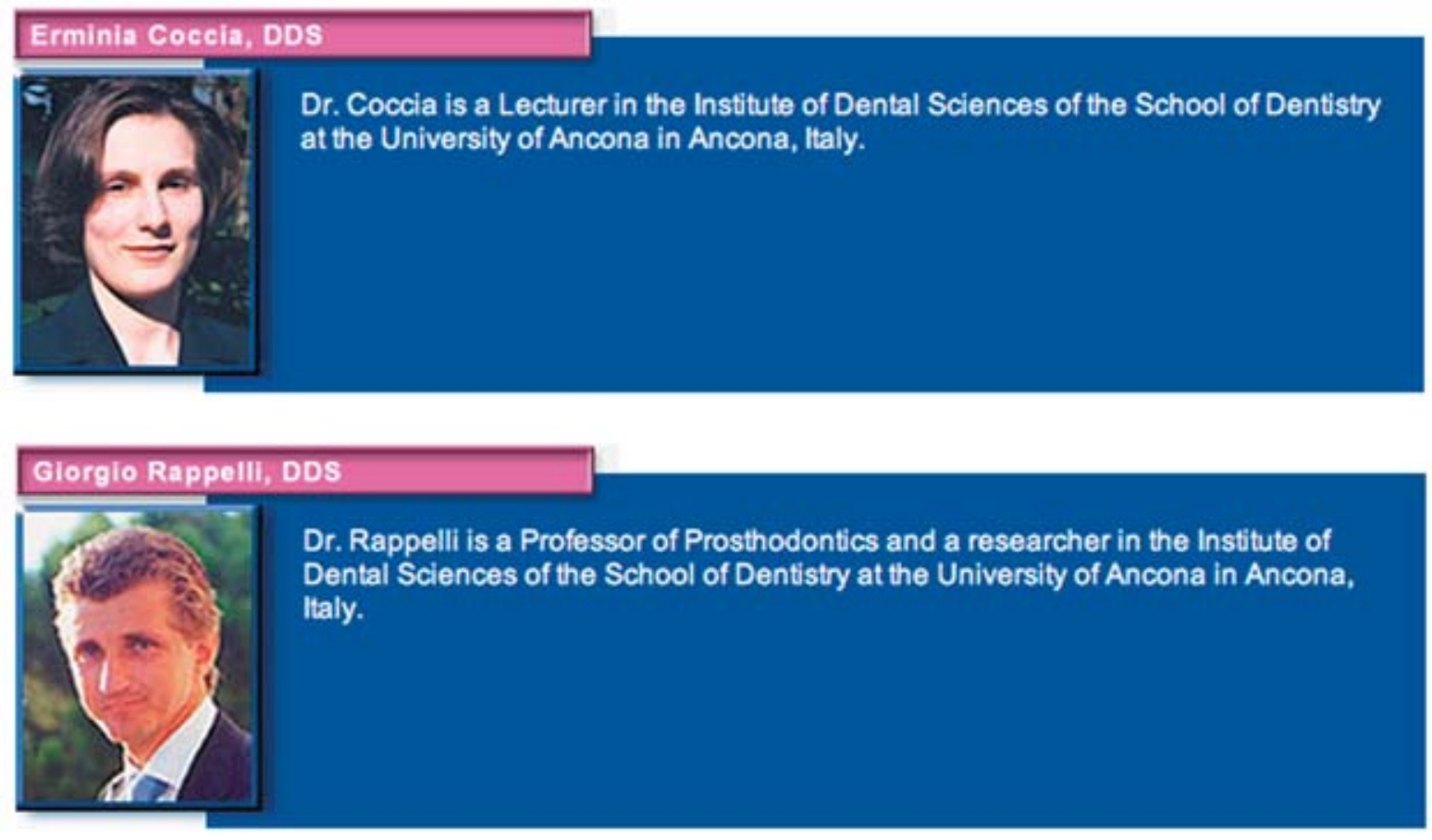